\title{
An optimised glucose oxidase bioelectrode exhibiting high performance direct electron transfer $\dagger$
}

\author{
Ross D. Milton, ${ }^{a}$ Jessica Baur, ${ }^{a}$ John R. Varcoe, ${ }^{a}$ Alfred E. Thumser ${ }^{b}$ and Robert C. T. Slade ${ }^{* a}$ \\ Received (in XXX, XXX) Xth XXXXXXXXX 200X, Accepted Xth XXXXXXXXX 200X \\ DOI: 10.1039/b000000x
}

A glucose oxidase (GOd) bioelectrode exhibiting high performance, direct electron transfer (DET) has been prepared. Unprecedented redox peak current densities of 1 $\mathrm{mA} \mathrm{cm}^{-2}$ were observed alongside a clear electrochemical 10 response to glucose. This system shows potential as a low cost, high performance enzymatic bioelectrode.

Glucose oxidase (GOd; EC 1.1.3.4), a flavo-protein (molecular weight of $c a .160 \mathrm{kDa}$ ) contains two flavin adenine dinucleotide 15 (FAD) redox centres located approximately $13 \AA$ into the protein structure $^{1}$. Typically, electron transfer from the FAD site to the electrode surface is restricted by the protein structure and electrochemical mediators are often used to transport electrons from the FAD sites to the electrode surface on oxidation of 20 glucose (mediated electron transfer, MET) ${ }^{2}$. Direct electron transfer (DET) from the FAD redox centres of the enzyme to the electrode is facilitated by using advanced materials such as graphene and carbon nanotubes ${ }^{1,3-5}$. DET by enzymes employed in bioelectronic devices has recently gained worldwide attention, 25 as there are many advantages with DET in biofuel cells and biosensors (as opposed to MET), such as the ability to reduce the size, toxicity and loss of potential difference in these devices ${ }^{6}$. Enzyme immobilization is essential for high performance and stability. The use of natural biocompatible polymers, such as 30 cellulose $^{5}$ and chitosan ${ }^{7,8}$, for the immobilisation of enzymes onto electrode surfaces facilitates low cost and simple electrode preparation. Previous work has shown the combination of multiwalled carbon nanotubes (MWCNT) and cellulose can provide a platform for DET of $\mathrm{GOd}^{5}$, and also provide electronically 35 conductive pathways through the cellulose.

In this study, 4 different methods of bioelectrode preparation were investigated with the aim of achieving improved DET with GOd and improved electrode temporal stability, using enzyme entrapment in a porous ionic liquid (1-ethyl-3-methylimidazolium 40 acetate, EMIM-acetate) reconstituted cellulose layer that was embedded with partially oxidised MWCNT ${ }^{5}$. MWCNT adsorbed onto the electrode surface increased electronic contact between the electrode and the enzyme whilst improving electrostatic interactions between the enzyme and MWCNT $^{9}$.

45 Scheme 1 summarises the methodology used to prepare the bioelectrodes. For all methods, each component deposited on the electrodes was dried under vacuum at $4^{\circ} \mathrm{C}$ before commencement of the next step; all electrodes were dried for $1 \mathrm{~h}$ under vacuum at $4^{\circ} \mathrm{C}$ (to aid adsorption) after addition of the MWCNT/EMIM-
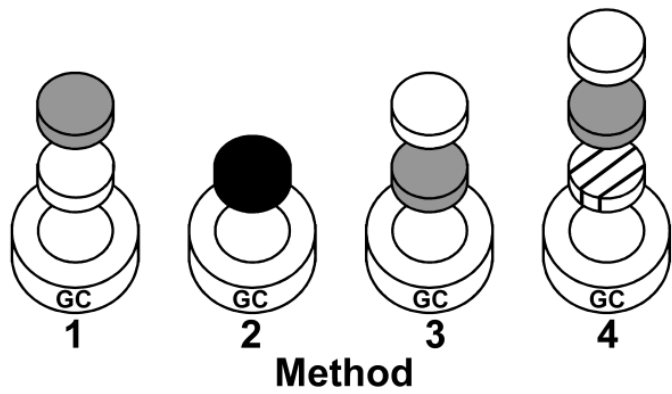

50



Scheme 1 Differing bioelectrode preparation methods

acetate/cellulose matrix. When not in use, electrodes were stored at $4^{\circ} \mathrm{C}$ in $200 \mu \mathrm{L}$ of nitrogen-saturated citrate buffer $\left(0.2 \mathrm{~mol} \mathrm{dm}^{-3}, \mathrm{pH}=6\right)$. Preliminary experiments had identified 55 this as the optimum $\mathrm{pH}$. EMIM-acetate is used to dissolve cellulose and simultaneously disperse the MWCNT.

In method 1, an ionic liquid reconstituted cellulose/MWCNT layer was firstly applied to a glassy carbon (GC) electrode surface and followed by adsorption of GOd. The ionic 60 liquid/cellulose/MWCNT matrix was also mixed with GOd and applied to a GC electrode, giving the method 2 bioelectrode. For method 3, GOd was directly adsorbed onto a GC electrode and covered with an ionic liquid reconstituted cellulose/MWCNT layer, whereas in method 4, a GC electrode was covered with ${ }_{65}$ MWCNT prior to GOd adsorption and finally covered with an ionic liquid reconstituted cellulose/MWCNT layer. The partially oxidised MWCNT were used to improve electronic connection between GOd and the GC electrode surface whilst attempting to improve bioelectrode stability. For MWCNT, the term "layer" 70 describes the application of a $10 \mu \mathrm{L}$ aqueous aliquot to the glassy carbon, followed by drying (1 layer, typically dry after $10 \mathrm{~min}$ ); 20 layers gave an optimal loading. For all methods, an enzyme loading of $0.8 \mathrm{mg}$ was used. The procedures undertaken to prepare these 4 different bioelectrode systems are detailed in the 75 Electronic Supplementary Information $\uparrow$. Fig. S.1. and Fig. S.2. present the optimisation of the MWCNT base layerst and the GOd loading, respectivelyt. 

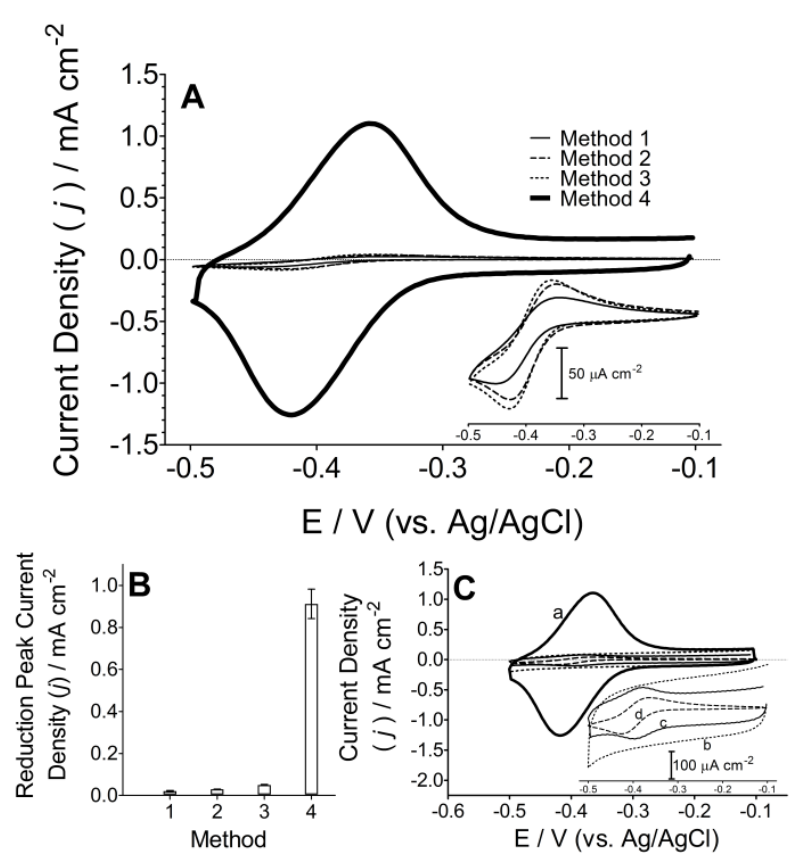

Fig. 1 (A) Cyclic voltammograms of GOd immobilisation methods $1-4$, with a scan rate of $100 \mathrm{mV} \mathrm{s}^{-1}$ in citrate buffer $\left(0.2 \mathrm{~mol} \mathrm{dm}^{-3}, \mathrm{pH}=6\right)$, $0.8 \mathrm{mg}$ GOd loadings and under anaerobic conditions. The inset focuses 5 on immobilisation methods $1-3$. (B) Mean reduction peak currents of replicate (individual electrodes) experiments with error bars (sample standard errors, replicates $(n)=3$ ). (C) Cyclic voltammograms of method 4 bioelectrodes containing the following combinations of constituents: (a) GC\&MWCNT/GOd/(MWCNT\&cellulose), (b) GC\&MWCNT/(MWCNT 10 \&cellulose), (c) GC\&MWCNT/GOd, and (d) GC/GOd/(MWCNT\& cellulose). The starting potential was $-0.1 \mathrm{~V}$.

Cyclic voltammetry was used to compare the different bioelectrode preparation methods (Fig. 1.A). The peak currents for electrodes prepared using method 4 are approximately twenty-

15 fold larger relative to electrodes prepared using methods $1-3$. The reduction and oxidation peaks obtained with electrodes prepared using method 4 are located at $-417 \mathrm{mV}$ and $-361 \mathrm{mV}$, respectively (Fig. 1.B). The associated geometric peak current densities of $1.0 \mathrm{~mA} \mathrm{~cm}{ }^{-2}$ are greatly improved in comparison to 20 work found in the literature employing expensive materials to achieve DET, giving approximate values of $0.18 \mathrm{~mA} \mathrm{~cm}(\mathrm{C} / \mathrm{Au}$ nano-particles, $\left.{ }^{10}\right), 0.32 \mathrm{~mA} \mathrm{~cm}^{-2}$ (gelatin/MWCNT, ${ }^{11}$ ) and 0.44 $\mathrm{mA} \mathrm{cm}{ }^{-2}$ (Pt nano-particles, $\left.{ }^{12}\right)$. The reduction and oxidation peaks represent DET for the reversible oxidation and reduction of the ${ }_{25} \mathrm{GOd}(\mathrm{FAD})$ active centres (equation 1$)^{13}$ :

$$
\mathrm{GOd}(\mathrm{FAD})+2 \mathrm{e}^{-}+2 \mathrm{H}^{+} \rightleftharpoons \operatorname{GOd}\left(\mathrm{FADH}_{2}\right)
$$

By considering the similarities between methods 3 and 4, it is hypothesised that the MWCNT/cellulose top layer primarily acts as an electronically conductive porous polymer, capable of 30 enhancing the stability of the bioelectrode by preventing enzyme leaching and providing an enzyme-friendly environment. Performances obtained with method 4 highlights the importance of the GC/MWCNT layer which allows GOd immobilization by adsorption prior to encapsulation in the MWCNT/cellulose 35 porous matrix. Fig. 1.C presents results from control experiments and highlights the importance of every component for the high performance method 4 bioelectrode.

The method 4 bioelectrode was also analysed under different scan rates to confirm successful enzyme immobilisation (Fig. 2).

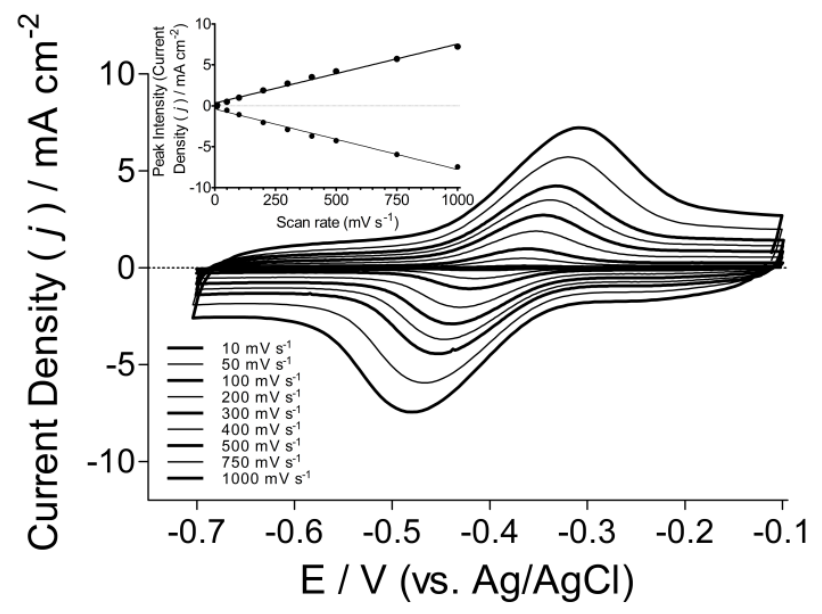

Fig. 2 Cyclic voltammograms of a complete method 4 bioelectrode at varying scan rates $\left(10,50,100,200,300,400,500,750\right.$ and $\left.1000 \mathrm{mV} \mathrm{s}^{-1}\right)$ with citrate buffer electrolyte $\left(0.2 \mathrm{~mol} \mathrm{dm} \mathrm{dm}^{-3}, \mathrm{pH}=6\right.$, anaerobic conditions). The starting potential was $-0.1 \mathrm{~V}$.

45 The ratio of the anodic and cathodic peak currents remained unchanged and a linear relationship between scan rate and peak intensity was observed, indicating that the electron transfer between the electrode architecture and GOd is a surfacecontrolled mechanism ${ }^{14,15}$.

so The response of the GOd bioelectrode to glucose and oxygen was investigated using cyclic voltammetry and method 4 preparation (Fig. 3.A). There is a clear shift to negative peak currents on purging the buffer with air in the absence of glucose. There is a marked decrease in reduction peak current, and a 55 concomitant increase in oxidation peak current with the addition of increasing concentrations of glucose (up to $0.8 \mathrm{mmol} \mathrm{dm}^{-3}$ ). The large increase of reduction peak current on the introduction of aerated buffer is probably due to oxygen reduction and regeneration of the oxidised GOd(FAD). The addition of glucose 60 to the aerobic buffer results in the decrease of the reduction peak current and an increase in oxidation peak current due to the regeneration of reduced $\mathrm{FADH}_{2}$ cofactor with glucose oxidation. The inset to Fig. 3.A shows the trend in reduction peak current on changing glucose concentration. Glucose oxidation is not known ${ }_{65}$ to occur in the absence of oxygen in this system. A recent publication suggested the inclusion of another enzyme to attempt to combat $\mathrm{H}_{2} \mathrm{O}_{2}$ production; it should be noted that glucose/GOd studies in that reference (strict DET) are performed in airsaturated solutions ${ }^{16}$.

70 DET current densities were large, reflecting the high loadings of GOd achievable with this low cost electrode architecture. A key goal for enzymatic fuel cells is to develop enzyme immobilisation strategies that allow high enzyme loadings for high current outputs. To confirm that the high current densities 75 measured were due to reversible oxido-reduction processes of the enzyme-bound cofactor and not dissociated cofactor, method 4 bioelectrodes were prepared with equivalent amounts of the FAD cofactor alone (no GOd) (Fig. 3.B). No changes to the peak currents were observed with the FAD-electrode in the presence of ${ }_{80}$ glucose, highlighting the need for the presence of the GOd holoenzyme for glucose oxidation, as previously reported ${ }^{17}$. Slightly higher peak currents (by approximately $43 \%$ ) and smaller peak separations (by approximately $24 \%$, in the absence of glucose) were observed for the FAD-only bioelectrode, indicating that the ${ }_{85}$ FAD can adsorb onto and interact directly with the MWCNT; this suggests that the presence of FAD in the GOd enzyme leads to a 

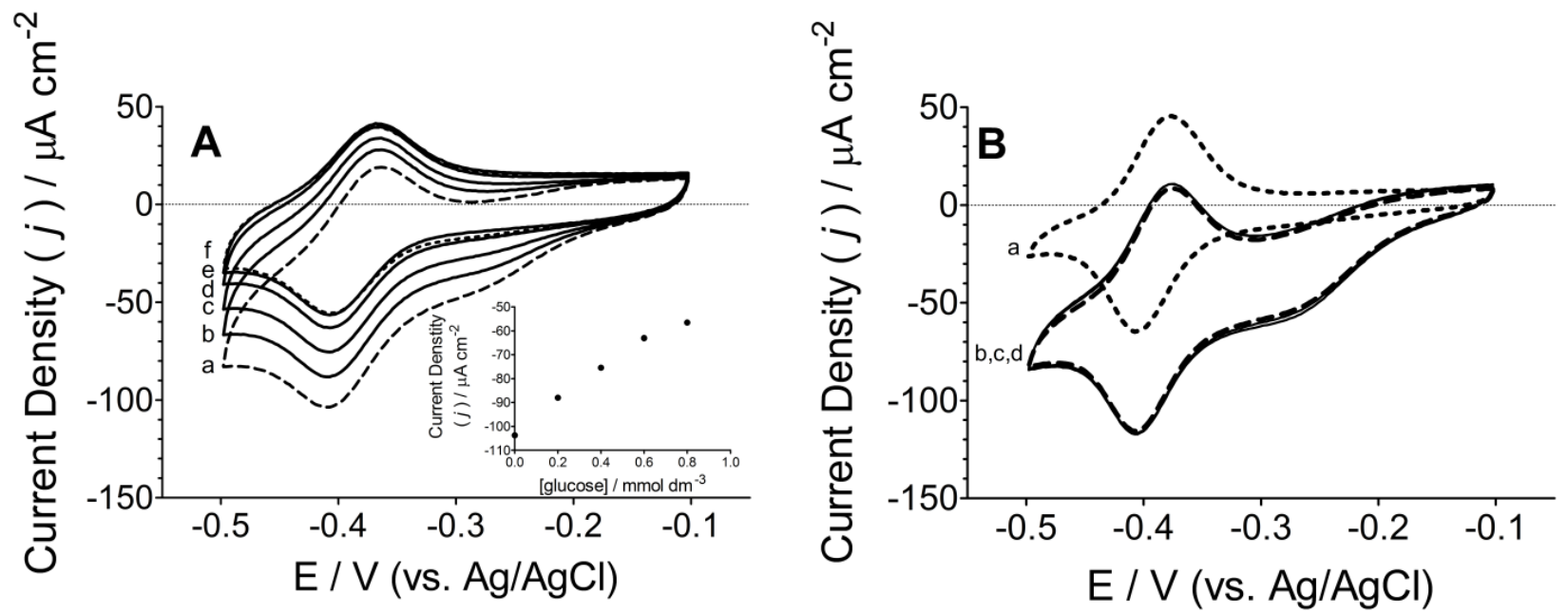

Fig. 3 (A) Cyclic voltammograms of a stabilised GOd bioelectrode (prepared using method 4 with $0.8 \mathrm{mg}$ GOd and 20 MWCNT primer layers) at a scan rate of $10 \mathrm{mV} \mathrm{s}^{-1}$ and with citrate buffer electrolyte $\left(0.2 \mathrm{~mol} \mathrm{dm}^{-3}, \mathrm{pH}=6\right)$ under: (a) aerobic with no glucose present, aerobic conditions with glucose concentrations of (b) $0.2 \mathrm{mmol} \mathrm{dm}^{-3}$, (c) $0.4 \mathrm{mmol} \mathrm{dm}^{-3}$, (d) $0.6 \mathrm{mmol} \mathrm{dm}$, and (e) $0.8 \mathrm{mmol} \mathrm{dm}^{-3}$, and (f) anaerobic with no glucose present. Inset: 5 reduction peak current intensities as a function of glucose concentration. (B) Cyclic voltammograms of a FAD cofactor electrode (comparable preparation to method 4) at a scan rate of $10 \mathrm{mV} \mathrm{s}^{-1}$ with citrate buffer electrolyte $\left(0.2 \mathrm{~mol} \mathrm{dm}^{-3}, \mathrm{pH}=6\right)$ under: (a) anaerobic and (b,c,d) aerobic conditions with varying glucose concentrations $\left(0-3 \mathrm{mmol} \mathrm{dm}^{-3}\right)$. The starting potential was $-0.1 \mathrm{~V}$.

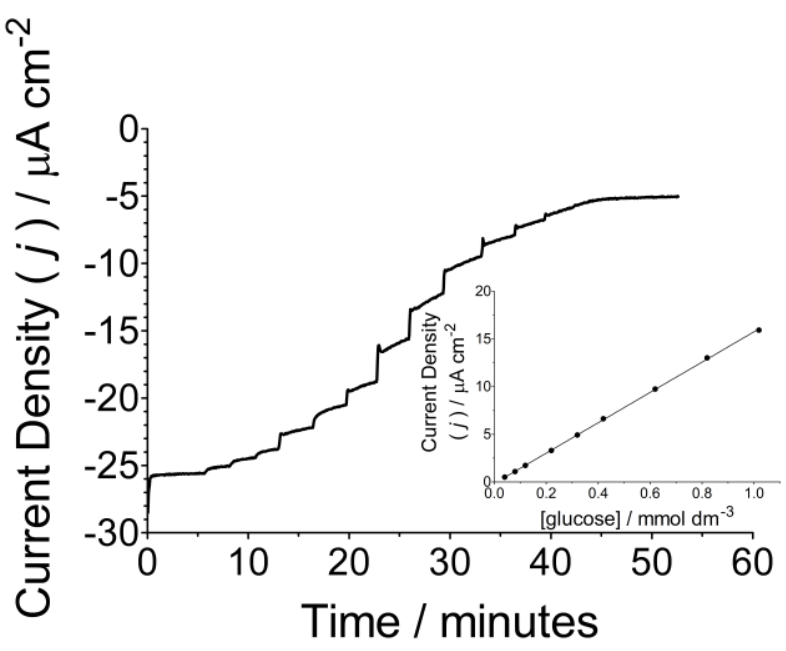

Fig. 4 Chronoamperometric response for glucose oxidation on a stabilised ${ }_{10}$ GOd bioelectrode prepared using method 4 with $0.8 \mathrm{mg}$ GOd and 20 MWCNT primer layers, performed on a RDE electrode held at $-0.5 \mathrm{~V}$ (vs. $\mathrm{Ag} / \mathrm{AgCl})$ in citrate buffer electrolyte $\left(0.2 \mathrm{~mol} \mathrm{dm}^{-3}, \mathrm{pH}=6\right)$ and at increasing glucose concentrations. Inset: linear range of glucose concentration $v s$. current density. The solutions were purged with air prior 15 to testing.

minor loss of electrical conductivity due to the increased distance between the cofactor and the MWCNT.

Chronoamperometry employing a rotating disc electrode (RDE) was used to evaluate the steady-state response of the GOd 20 bioelectrode (Fig. 4). The enzyme turnover efficiency for the electrode $^{18}$ was determined to be $74 \mathrm{~s}^{-1}$ (Electronic Supplementary Information $\dagger$ ). This value is lower than that reported by Willner and co-workers ${ }^{19}$, who employed electrochemical mediators (MET), which significantly enhance 25 electron transfer performance, and thus enzyme performance, to improve electron transfer between GOd and an electrode (yielding approximately $700 \mathrm{~s}^{-1}$ ). However, in direct comparison to work by Gooding and co-workers ${ }^{18}$, who used "molecular wires" to enhance electron transfer of GOd whilst retaining DET 30 (to yield approximately $1.1 \mathrm{~s}^{-1}$ ), the value for enzyme turnover presented in this work is very significantly improved.

The stabilities of the bioelectrodes were studied using cyclic voltammetry at hourly intervals. The activity of the different bioelectrodes after $1 \mathrm{~h}$ was determined by comparing the 35 magnitude of the reduction peak currents obtained under identical conditions at $\mathrm{t}=0$ and $1 \mathrm{~h}$. Rapid activity loss was observed for methods $1-3$ bioelectrodes with $1 \%, 5 \%$, and $6 \%$ of the initial peak currents remaining, respectively. The method 4 bioelectrode exhibited high stability; $89 \%$ of the initial reduction peak current 40 remained after $1 \mathrm{~h}$. Furthermore, good stability was still evident after $6 \mathrm{~d}$, with $42 \%$ remaining reduction peak current. The remaining activity at this stage is a marked improvement on prior literature reports.

\section{Conclusions}

${ }_{45}$ This work reports a bioelectrode containing glucose oxidase (GOd) and MWCNT that exhibits direct electron transfer (DET) with a considerably enhanced current output and enzyme turnover compared to previously reported GOd-based bioelectrodes that employ nano-gold, nano-platinum or carbon nanotubes ${ }^{10-12}$. The 50 methodology presented yields a low cost enzymatic biofuel cell anode configuration that retains high efficiency DET between the enzyme and the electrode. This high efficiency DET is vital for the development of high performance enzyme bioelectrodes for enzymatic fuel cells with power outputs approaching those of ${ }_{55}$ classical chemical fuel cells.

\section{Acknowledgements}

This research was supported by the U.K. Engineering and Physical Sciences Research Council's Supergen Biological Fuel ${ }_{60}$ Cells Consortium programme (EPSRC contract EP/H019480/1). John Varcoe and the Autolab PGSTAT302N are also funded by EPSRC contract EP/I004882/1 (EPSRC Leadership Fellowship grant).

\section{Notes and references}


${ }^{a}$ Department of Chemistry, University of Surrey, Guildford, Surrey GU2

$7 X H$, United Kingdom

${ }^{b}$ Department of Biochemistry and Physiology, University of Surrey,

Guildford, Surrey GU2 $7 X H$, United Kingdom

5*E-mail: r.slade@surrey.ac.uk

$\dagger$ Electronic Supplementary Information (ESI) available: List of chemicals; Instrumentation and procedures. See DOI: 10.1039/b000000x/

10 1. D. Ivnitski, B. Branch, P. Atanassov and C. Apblett, Electrochem. Commun., 2006, 8, 1204-1210.

2. C. X. Guo and C. M. Li, Phys. Chem. Chem. Phys., 2010, 12, 1215312159.

3. C. X. Cai and J. Chen, Anal. Biochem., 2004, 332, 75-83.

15 4. P. Wu, Q. A. Shao, Y. J. Hu, J. A. Jin, Y. J. Yin, H. Zhang and C. X. Cai, Electrochimica Acta, 2010, 55, 8606-8614.

5. X. E. Wu, F. Zhao, J. R. Varcoe, A. E. Thumser, C. Avignone-Rossa and R. C. T. Slade, Bioelectrochemistry, 2009, 77, 64-68.

6. V. Coman, R. Ludwig, W. Harreither, D. Haltrich, L. Gorton, T. 20 Ruzgas and S. Shleev, Fuel Cells, 2009, 10, 9-16.

7. J. Tkac, J. W. Whittaker and T. Ruzgas, Biosens. Bioelectron., 2007, 22, 1820-1824.

8. X. D. Zeng, X. F. Li, L. Xing, X. Y. Liu, S. L. Luo, W. Z. Wei, B. Kong and Y. H. Li, Biosens. Bioelectron., 2009, 24, 28982903.

9. J. Baur, A. Le Goff, S. Dementin, M. Holzinger, M. Rousset and S. Cosnier, Int. J. Hydrogen Energy, 2011, 36, 12096-12101.

10. L. X. Wang, J. Bai, X. J. Bo, X. L. Zhang and L. P. Guo, Talanta, 2011, 83, 1386-1391.

30 11. A. P. Periasamy, Y. J. Chang and S. M. Chen, Bioelectrochemistry, 2011, 80, 114-120.

12. W. J. Li, R. Yuan, Y. Q. Chai, H. A. Zhong and Y. Wang, Electrochim. Acta, 2011, 56, 4203-4208.

13. Q. H. Gibson, V. Massey and B. E. P. Swoboda, J. Biol. Chem., 1964, 239, 3927-3934.

14. A. J. Bard and L. Faulkner, in Electrochemical Methods: Fundamentals and Applications, ed. E. Swain, John Wiley \& Sons, New Jersey, 2 edn., 2001, ch. 14: Electroactive layers and modified electrodes, pp. 590-593.

40 15. E. Laviron, J. Electroanal. Chem., 1979, 100, 263-270.

16. A. Zebda, C. Gondran, A. Le Goff, M. Holzinger, P. Cinquin and S. Cosnier, Nat. Commun., 2011, 2, 1-6.

17. D. Shan, J. Zhang, H. G. Xue, S. N. Ding and S. Cosnier, Biosens. Bioelectron., 2010, 25, 1427-1433.

45 18. G. Liu, M. N. Paddon-Row and J. J. Gooding, Electrochem. Commun., 2007, 9, 2218-2223.

19. M. Zayats, E. Katz and I. Willner, J. Am. Chem. Soc., 2002, 124, 2120-2121. 


\title{
Electronic Supplementary Information for:
}

\section{An optimised glucose oxidase bioelectrode exhibiting high performance direct electron transfer}

\author{
Ross D. Milton, ${ }^{a}$ Jessica Baur, ${ }^{a}$ John R. Varcoe, ${ }^{a}$ Alfred E. Thumser ${ }^{b}$ and \\ Robert C. T. Slade $*^{a}$
${ }^{a}$ Department of Chemistry, University of Surrey, Guildford, Surrey GU2 7XH, United Kingdom
${ }^{\mathrm{b}}$ Department of Biochemistry and Physiology, University of Surrey, Guildford, Surrey GU2 7XH, United Kingdom

\section{E-mail: $\underline{\text { r.slade@surrey.ac.uk }}$}

$\underline{\text { Figures }}$

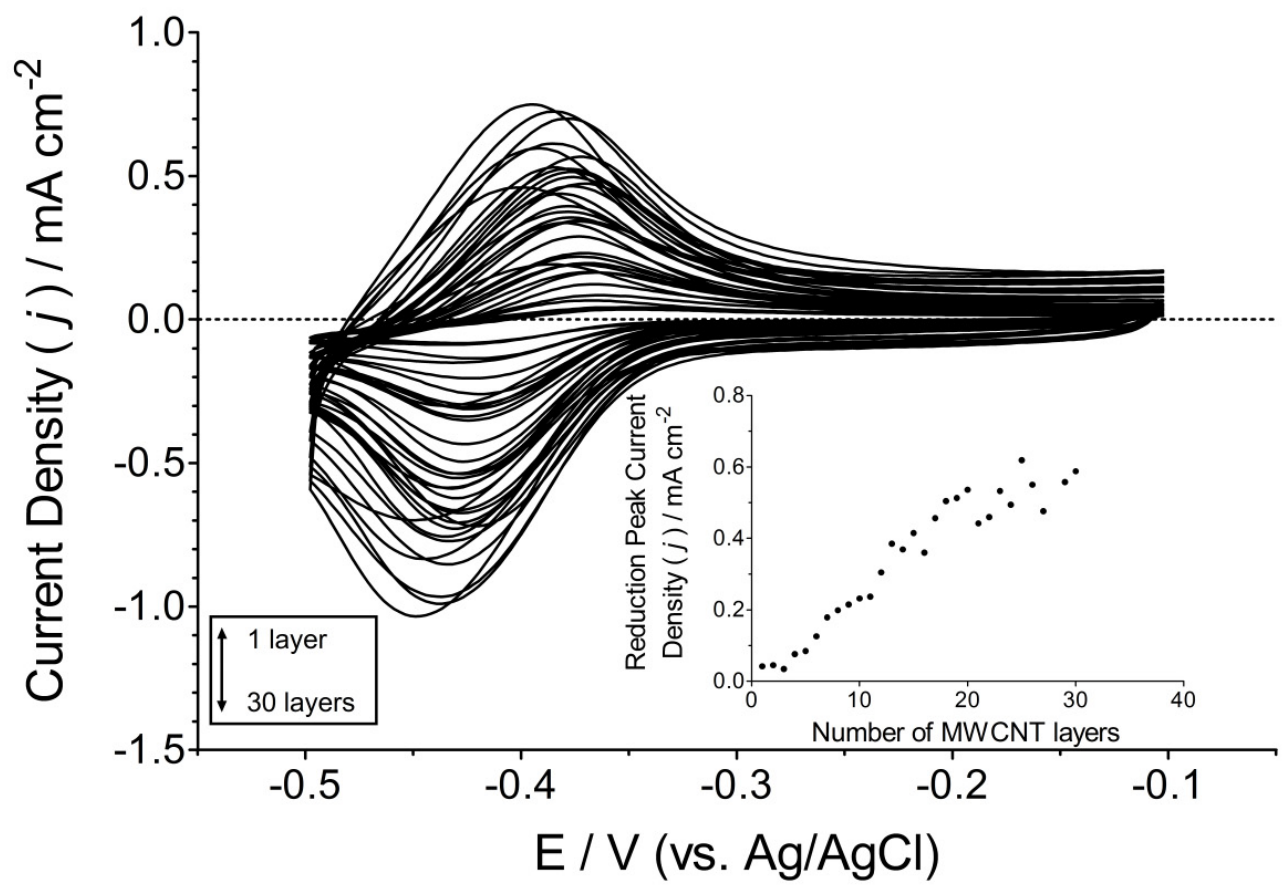

Fig. S.1. - Cyclic voltammograms showing the effect on current intensities by increasing the number of MWCNT "primer" layers), at a scan rate of $100 \mathrm{mV} \mathrm{s}^{-1}$ with citrate buffer electrolyte $\left(0.2 \mathrm{~mol} \mathrm{dm}^{-3}, \mathrm{pH}=6\right)$ and a GOd loading of $1 \mathrm{mg}$. The starting potential was $-0.1 \mathrm{~V}$. 


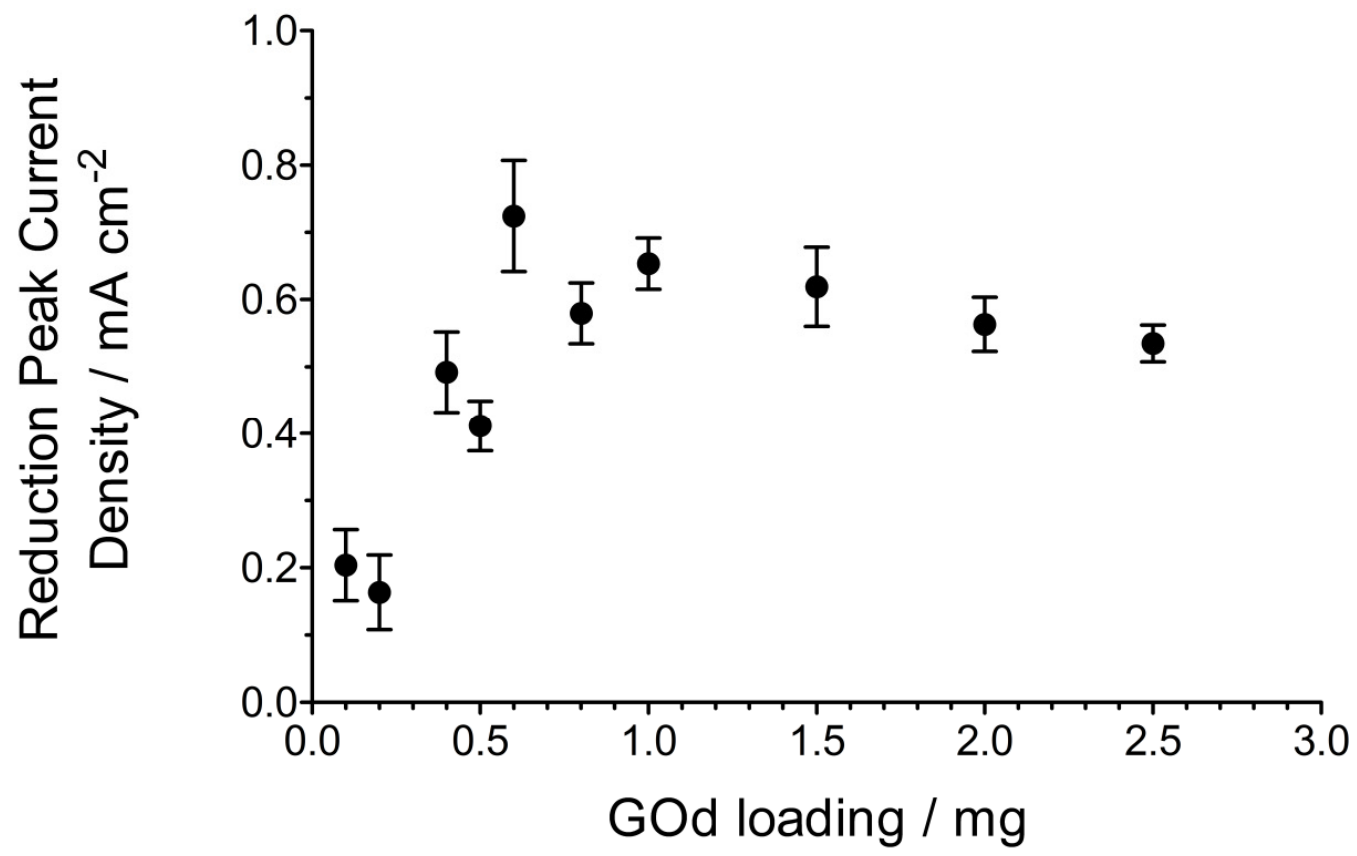

Fig. S.2. - The modulus of reduction peak current $v$ s. enzyme loading (GOd) extracted from cyclic voltammograms, at a scan rate of $100 \mathrm{mV} \mathrm{s}^{-1}$ with citrate buffer electrolyte $\left(0.2 \mathrm{~mol} \mathrm{dm}^{-3}, \mathrm{pH}=6\right)$ and a 20 MWCNT layers, $\mathrm{n}=3$. The starting potential was -0.1 $\mathrm{V}$.

\section{$\underline{\text { Calculation of the Turnover Rate (TR) }}$}

$i_{P}=\frac{n^{2} F^{2}}{4 R T} v A \Gamma^{*}{ }_{O} \quad$ Equation $1^{1}$

The surface coverage of the Method 4 bioelectrode was determined using Equation 1, where $i_{P}=$ peak current, $n=$ number of electrons transferred, $F=$ Faraday's constant, $\mathrm{R}=$ gas constant, $\mathrm{T}=$ temperature, $v=$ scan rate, $\mathrm{A}=$ area of electrode and $\Gamma^{*} \mathrm{O}=$ surface coverage. The surface coverage of GOd on the method 4 bioelectrode was calculated to be $1.398 \times 10^{-12} \mathrm{~mol} \mathrm{~cm}^{-2}$.

$T R=\frac{I_{c a t} / A}{n F \Gamma_{G O d}} \quad$ Equation $2^{2}$

The turnover rate at a saturated electrode was calculated by using equation 2 , where $\mathrm{I}_{\text {cat }}$ is the current at the glucose saturation. The turnover rate was calculated to be $74.1 \mathrm{~s}^{-1}$.

Chemicals

Nanocyl-3100 MWCNTs were supplied by Nanocyl (Belgium). GOd (Aspergillus niger, $200 \mathrm{U} \mathrm{mg}^{-1}$ ), glucose, microcrystalline cellulose, 1-ethyl-3-methylimidazolium acetate 
(EMIM-acetate), citric acid, and sodium citrate were purchased from Sigma-Aldrich (UK). Partially oxidised MWCNTs were prepared by refluxing in aqueous $\mathrm{HNO}_{3}(2.6$ mol $\mathrm{dm}^{-3}$ ) for $10 \mathrm{~h}$, rinsing with water until a neutral $\mathrm{pH}$ was obtained and drying the product in an oven at $80^{\circ} \mathrm{C}$ for $12 \mathrm{~h}^{3}$. Glucose solutions were allowed to mutarotate for 1 $\mathrm{d}$ and were kept refrigerated. Ultrapure water was used to prepare all solutions (18.2 $\mathrm{M} \Omega$ $\mathrm{cm}^{-1}$, Select Fusion system from Purite, U.K.).

\section{$\underline{\text { Instrumentation and Procedures }}$}

Electrochemical analyses were carried out using an Autolab PGSTAT302N (EcoChemie, Netherlands) in a $15 \mathrm{~cm}^{3}$ three electrode water-jacketed cell at $22 \pm 1^{\circ} \mathrm{C}$ with a Pt wire counter electrode, and an $\mathrm{Ag} / \mathrm{AgCl}\left(\mathrm{NaCl}(\mathrm{aq}), 3 \mathrm{~mol} \mathrm{dm}^{-3},+0.196 \mathrm{~V}\right.$ vs. SHE at $\left.298 \mathrm{~K}\right)$ reference electrode. An aqueous citrate buffer $\left(0.2 \mathrm{~mol} \mathrm{dm}^{-3}, \mathrm{pH}=6\right)$ purged with either high-purity nitrogen or air was used as electrolyte.

Before use, glassy carbon electrodes $(\mathrm{GC}$, diameter $=3 \mathrm{~mm})$ were polished with $0.5 \mu \mathrm{m}$ alumina, and ultrasonically washed in deionised water. Stable MWCNT dispersions in water $\left(0.1 \mathrm{mg} \mathrm{cm} \mathrm{cm}^{-3}\right)$ were obtained by sonication for $5 \mathrm{~min}$. The EMIMacetate/MWCNT/cellulose matrix was prepared as follows: cellulose $(3 \% \mathrm{w} / \mathrm{w})$ was dissolved in EMIM-acetate at $70^{\circ} \mathrm{C}$ for $1 \mathrm{~h}$ under sonication, and this solution was then ground with MWCNT $(0.1 \% \mathrm{w} / \mathrm{w})$ in an agate mortar under nitrogen. The resulting dispersion was transferred to a sealed tube and stored in a desiccator until use.

In method $1,10 \mu \mathrm{L}$ of the MWCNT/EMIM-acetate/cellulose matrix was applied to the electrode surface; the MWCNT/EMIM-acetate/cellulose matrix modified electrode was then soaked in ultrapure water to remove the EMIM-acetate from the matrix, yielding a MWCNT-embedded cellulose layer on the electrode surface. A $10 \mu \mathrm{L}$ GOd aliquot (80 $\mathrm{mg} \mathrm{cm}{ }^{-3}$ ) was then added onto the MWCNT/cellulose layer.

Method 2 involved the direct dissolution of the lyophilized enzyme powder $\left(80 \mathrm{mg} \mathrm{cm}^{-3}\right)$ with the MWCNT/EMIM-acetate/cellulose matrix. The mixture was sonicated for $1 \mathrm{~h}$ to maximise dispersion. The matrix was added to the electrode and the EMIM-acetate was removed as before.

Method 3 involved enzyme adsorption in reverse order to method 1 . A $10 \mu \mathrm{L}$ aliquot of the GOd solution $\left(80 \mathrm{mg} \mathrm{cm}^{-3}\right)$ was added to the electrode surface and dried. The MWCNT/EMIM-acetate/cellulose layer was then added to the electrode and the EMIMacetate removed as before.

Method 4 involved the pre-treatment of the GC electrodes with MWCNT by depositing successive layers (20 layers) of $10 \mu \mathrm{L}$ aliquots of aqueous MWCNT dispersion $(0.1 \mathrm{mg}$ $\mathrm{cm}^{-3}$ ). The electrodes were then prepared in an identical fashion to method 3 .

During bioelectrode preparation, good surface coverage was achieved for method 4 following the addition of the MWCNT/cellulose layer, whilst surface defects were observed by eye for methods $1-3$. Method 2 exhibited poor repeatability and the low magnitude of the observed currents is most probably due to loss of enzyme activity 
during sonication. Desorption of GOd from the MWCNT/cellulose matrix was observed during electrochemical analysis of method 1 bioelectrodes, which again highlights the importance of the MWCNT/cellulose encapsulation.

\section{References}

1. A. J. Bard and L. Faulkner, in Electrochemical Methods: Fundamentals and Applications, ed. E. Swain, John Wiley \& Sons, New Jersey, 2 edn., 2001, ch. 14: Electroactive layers and modified electrodes, pp. 590-593.

2. G. Liu, M. N. Paddon-Row and J. J. Gooding, Electrochem. Commun., 2007, 9, 2218-2223.

3. X. E. Wu, F. Zhao, J. R. Varcoe, A. E. Thumser, C. Avignone-Rossa and R. C. T. Slade, Bioelectrochemistry, 2009, 77, 64-68. 